\title{
Role of gastro-oesophageal reflux in infant irritability
}

\author{
R G Heine, A Jaquiery, L Lubitz, D J S Cameron, A G Catto-Smith
}

\begin{abstract}
Gastro-oesophageal reflux (GOR) disease may cause excessive crying in infants. The role of GOR was evaluated in infant irritability and an attempt was made to define clinical predictors of pathological reflux. Seventy consecutively admitted infants with irritability and presumptive GOR were retrospectively reviewed. All had undergone prolonged oesophageal pH monitoring. Pathological GOR was defined as a fractional refiux time of $\geqslant 10 \%$ and was significantly less common in infants under 3 months (one of $24 ; 4 \cdot 2 \%$ ) than in older infants (10 of $46 ; 21 \cdot 7 \%$ ). All infants with pathological GOR presented with frequent vomiting, and 'silent' pathological reflux did not occur. Poor weight gain, feeding refusal, backarching, and sleep disturbance were not significantly associated with pathological GOR. The results suggest that pathological GOR is an unlikely cause of infant irritability under the age of 3 months.

(Arch Dis Child 1995; 73: 121-125)
\end{abstract}

Keywords: irritability, infantile colic, gastro-oesophageal reflux.

Crying is a normal form of communication of the young infant. Most parents quickly learn to distinguish between different reasons for crying. Crying patterns during infancy vary with age and usually peak in frequency at about 6 weeks to 3 months, with the majority of crying episodes occurring in the late afternoon and early evening hours. ${ }^{12}$ Terms such as infantile colic, infant irritability, or excessive crying describe the common phenomenon of paroxysmal episodes of apparently unexplained prolonged crying during early infancy. In infants under 3 months of age, crying for more than three hours per day on more than three days a week is considered pathological. ${ }^{3}$ Excessive crying often creates stress and anxiety in the family which may have adverse effects on the often already overstimulated infant. ${ }^{45}$ The response of parents to an infant with excessive crying is significantly influenced by their social network, and mothers of first born infants are more likely to seek medical advice. ${ }^{2}$ Psychosocial factors such as stress or physical symptoms during pregnancy, dissatisfaction with the sexual relationship, and negative experiences during childbirth have been found to be associated with an increased risk of developing infantile colic. $^{6}$ Maternal depression during pregnancy ${ }^{7}$ or the postnatal period ${ }^{8}$ may also adversely affect the mother-child relationship and result in excessive crying.

The term 'colic' implies that infant irritability is related to colonic spasm or flatulence. The issue of whether excessive crying in infancy really is related to episodes of pain or whether it is a predominantly behavioural phenomenon remains unresolved. 9 Organic causes such as urinary tract infections ${ }^{10}$ and food intolerance ${ }^{11}$ may cause irritable behaviour in some infants, but in the majority of infants no organic cause of excessive crying is found despite extensive medical investigations. ${ }^{9}$

In recent years much attention has been focused on the role of gastro-oesophageal reflux (GOR) as a cause of infant irritability. ${ }^{12-16}$ GOR is usually regarded as a significant clinical problem when it results in adverse effects such as oesophageal injury, aspiration, or failure to thrive. In general, the duration of oesophageal acid exposure correlates closely with the likelihood of oesophagitis. Large studies of otherwise normal infants have established that infants reflux more frequently than adults, and different normal values apply for frequency of reflux episodes and the fractional reflux time during the first year of life. ${ }^{17}$ The clinician often finds it difficult to determine whether reflux exceeds the physiological amount or is responsible for episodes of irritability. ${ }^{13}$ Oesophageal $\mathrm{pH}$ monitoring is considered the most valuable test to predict whether the degree of reflux is likely to cause oesophagitis and whether reflux episodes coincide with irritable behaviour of the infant. ${ }^{18} 19$ This test, however, may not be readily available outside the hospital setting.

The clinical approach to irritable infants is heterogeneous, ranging from reassurance and behaviour intervention, ${ }^{45}$ to formula changes, ${ }^{102021}$ and treatment with anticholinergic $^{22}$ or antireflux medications. Clinical predictors are needed to identify irritable infants with pathological GOR. The aims of our study were to evaluate the role of increased GOR in irritable infants, and to define clinical predictors of excessive GOR in order to identify infants who warrant further investigation and treatment.

\section{Patients and methods}

We reviewed the medical records of all infants under the age of 12 months who were admitted to the Royal Children's Hospital, Melbourne, between January and December 1993, with significant irritability and a presumptive diagnosis of GOR. Only infants who 


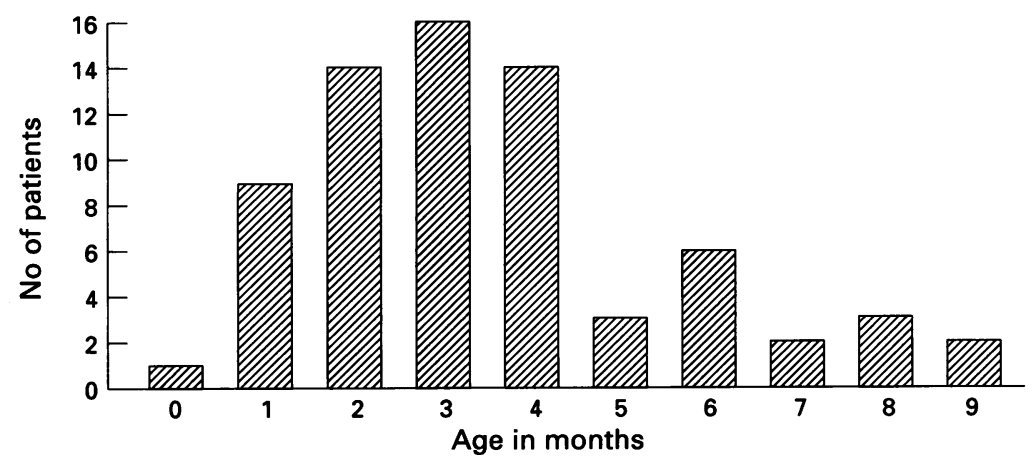

Age distribution of the study population ( $n=70$, median age 3.8 months, lower to upper quartile range $2 \cdot 5$ to $4 \cdot 8$ months).
NUTRITIONAL ASSESSMENT

Body weight was measured at the time of admission to hospital, and $\mathrm{Z}$ scores for weight for age were calculated using an anthropometric software program (Epi Info 5.01, Centers for Disease Control). The $\mathrm{Z}$ score for weight for age is calculated by subtracting the median weight of the reference population from the child's weight, divided by the SD of the reference population at that age. ${ }^{24}$

\section{STATISTICAL ANALYSES}

This included calculation of means (quoted as mean (SD)) and medians (upper to lower quartile range), $\chi^{2}$ test, two sample Student's $t$ test for means, and weighted $\kappa$ test. ${ }^{25}$ Results were considered statistically significant if they reached the $95 \%$ level $(p<0.05)$. Analyses were performed using the PC software packages MSExcel 5.0 for Windows (Microsoft Corporation, and Minitab 10.1 for Windows (Minitab Inc). were collected from the charts: age at admission, sex, past medical history, symptoms, feeding history, medications, weight gain, and results of investigations (oesophageal pH monitoring, oesophageal histology, barium swallow).

\section{AGE AND SEX}

During the 12 month study period, 70 irritable infants who fulfilled the study criteria were admitted to hospital ( 44 boys, 26 girls, male to female ratio $1 \cdot 7: 1)$. Fifty infants $(71 \cdot 4 \%)$ were referred directly from paediatricians, 13 infants $(18.6 \%)$ from general practitioners, and seven $(10.0 \%)$ from within the hospital. The median age at the time of hospital admission was 3.8 months (range 4 weeks -9 months, lower to upper quartile range $2 \cdot 5-4 \cdot 8$ months). Twenty four infants $(34.3 \%)$ were younger than 3 months, $33(47 \cdot 1 \%)$ were between 3 and 6 months, and $13(18.6 \%)$ were between 6 and 9 months old. The age distribution is summarised in the figure.

\section{OESOPHAGEAL PH MONITORING}

All patients underwent prolonged oesophageal $\mathrm{pH}$ monitoring ${ }^{19}$ which was performed by an experienced gastroenterology technician using a Digitrapper (Synectics Medical) with an antimony electrode. Antireflux medications were stopped at least 48 hours before $\mathrm{pH}$ monitoring. The $\mathrm{pH}$ probe was calibrated using two standardised buffer solutions $(\mathrm{pH}$ 1.04 and $\mathrm{pH} 7 \cdot 0$ ), inserted pernasally and positioned in the lower oesophagus. The exact position was determined by use of a formula ${ }^{23}$ which is based on height, and by retraction of the probe from the stomach after having obtained an acidic reading. Infants were breast fed or received their usual formula during the study period and were not offered acidic drinks. A diary with information on feeding time and posture was kept for 24 hours. Data were analysed with help of a PC software program (EsopHogram, Gastrosoft Inc). A fractional reflux time of $\geqslant 10 \%$ with an oesophageal $\mathrm{pH}$ of below 4.0 was considered pathological. ${ }^{17}$

\section{Results}

FEEDING HISTORY AND WEIGHT GAIN

Thirty five infants $(50 \%)$ had been breast fed, and of these 23 had been breast fed for less than one month. At the time of hospital admission, 13 infants $(18.6 \%)$ were predominantly breast fed (mean age breast fed $4 \cdot 1 \quad(2.0)$ months $v$ bottle fed $4.0 \quad(2 \cdot 0)$ months, $\mathrm{p}=0.96$ ). Most bottle fed infants had been given a sequence of different formulas which had included cows' milk based, lactose-free cows' milk based, soya, or a protein hydrolysate. At the time of hospital admission, 29 of the $57(50.9 \%)$ infants on formula were being fed protein hydrolysate. The mean number of different formulas used in the bottle fed infants was $2 \cdot 6(1 \cdot 2)$ (range 1-6).

Thirty five of the infants $(50.0 \%)$ had had feeding difficulties, as perceived by their parents. Three infants with marked failure to thrive were being fed by nasogastric tube on admission. Twenty six had episodes of distress with backarching and crying during feeding, two had frequent choking episodes, and four were not interested in feeding. No significant age difference was found between infants with and without feeding difficulties $(3 \cdot 8(2 \cdot 3) v 4 \cdot 2$ $(1 \cdot 7)$ months, $p=0 \cdot 39$ ).

The $\mathrm{Z}$ score for weight for age was normally distributed with a mean $Z$ score of -0.26 $(0.92)$ (median $Z$ score -0.20 , lower to upper quartile range -0.90 to 0.43 ). Eleven infants $(15 \cdot 7 \%)$ presented with failure to thrive. The mean Z score of infants who presented with failure to thrive was significantly lower than $(0.91), p=0.004)$. There was, however, no significant difference in $\mathrm{Z}$ scores for weight for age between the infants with $(-0.26(0.95))$ and those without perceived feeding difficulties $(-0.27(0.90), p=0.98)$.

OESOPHAGEAL PH MONITORING

All 70 infants underwent prolonged oesophageal $\mathrm{pH}$ monitoring. The mean duration of that of other infants $(-0.93(0.68) v-1.4$ 
Table 1 Results of prolonged oesophageal pH monitoring in the study population

\begin{tabular}{|c|c|c|c|c|}
\hline & \multirow[b]{2}{*}{$\begin{array}{l}\text { Total } \\
(n=70)\end{array}$} & \multicolumn{2}{|l|}{ Age (months) } & \multirow[b]{2}{*}{$p$ Value } \\
\hline & & $\begin{array}{l}<3 \\
(n=24)\end{array}$ & $\begin{array}{l}\geqslant 3 \\
(n=46)\end{array}$ & \\
\hline $\begin{array}{l}\text { No of reflux episodes } / 24 \text { hours } \\
\text { No of reflux episodes }>5 \text { min } \\
\text { Duration longest reflux episode (min) } \\
\text { Fractional reflux time (\%) }\end{array}$ & $\begin{array}{c}34 \cdot 0(18 \cdot 7) \\
3 \cdot 3(3 \cdot 2) \\
14 \cdot 6(15 \cdot 6) \\
5 \cdot 6(4 \cdot 7)\end{array}$ & $\begin{aligned} & 24 \cdot 0(12 \cdot 6) \\
& 2 \cdot 6(2 \cdot 7) \\
& 11 \cdot 5(10 \cdot 1) \\
& 3 \cdot 9(3 \cdot 2)\end{aligned}$ & $\begin{array}{c}39 \cdot 2(19 \cdot 4) \\
3 \cdot 6(3 \cdot 5) \\
16 \cdot 3(17 \cdot 7) \\
6 \cdot 5(5 \cdot 2)\end{array}$ & $\begin{array}{l}0.0002 \\
0 \cdot 20 \\
0 \cdot 15 \\
0 \cdot 012\end{array}$ \\
\hline
\end{tabular}

Infants 3 months or older had significantly more reflux episodes and a significantly greater fractional reflux time than infants younger than 3 months.

the studies was $22 \cdot 8(2 \cdot 1)$ hours. The mean number of reflux episodes per 24 hours was $33.9(18.7)$ episodes. The mean fractional reflux time was $5 \cdot 6(4 \cdot 7) \%$ (range $0-25 \cdot 5 \%$, lower to upper quartile range $2 \cdot 6-7 \cdot 1 \%$ ). The fractional reflux time was $\geqslant 10 \%$ in 11 $(15 \cdot 7 \%)$, between $\geqslant 5-<10 \%$ in $19(27 \cdot 1 \%)$, and $<5 \%$ in $40(57 \cdot 1 \%)$ of the infants. Both the mean number of reflux episodes per 24 hours and the mean fractional reflux time were significantly higher in infants aged 3 months or older compared with infants under 3 months of age (table 1). Pathological reflux (fractional reflux time $\geqslant 10 \%$ ) was significantly more common in infants 3 months or older than in younger infants (one of $24 v 10$ of 46, $\left.\chi^{2}=3 \cdot 68, p=0 \cdot 05\right)$.

There was no significant difference in $\mathrm{Z}$ scores for weight for age between infants with or without pathological GOR (fractional reflux time $\geqslant 10 \%)(-0.49(1.14) v-0.21(0.86)$, $\mathrm{p}=0 \cdot 46)$. Of the 11 infants with pathological reflux only three presented with failure to thrive, and there was no significant association between pathological GOR and failure to thrive (three of $11 v$ eight of $59, \chi^{2}=1 \cdot 32$, $\mathrm{p}=0 \cdot 25)$.

\section{SYMPTOMS OF GOR}

Based on the history and clinical observation during hospital admission, vomiting or regurgitation was graded as either 'frequent vomiting' (that is, occurring after most feeds), or 'infrequent or no vomiting' (table 2). All infants with a fractional reflux time $\geqslant 10 \%$ presented with frequent vomiting. None of the infants with absent or infrequent vomiting had significant reflux. The association between vomiting and severity of GOR was significant $\left(\chi^{2}=4 \cdot 52, p=0 \cdot 034\right)$, and absence of vomiting was a reliable predictor of non-pathological reflux.

Four infants $(5 \cdot 7 \%)$ presented with haematemesis. Three had endoscopic evidence of oesophagitis and pathological $\mathrm{pH}$ monitoring studies (mean fractional reflux time 15.2

Table 2 Presence of a history of vomiting in 70 irritable infants in relation to the severity of GOR; values are number (\%)

\begin{tabular}{llll}
\hline $\begin{array}{l}\text { Fractional } \\
\text { reflux time }\end{array}$ & No & $\begin{array}{l}\text { Frequent } \\
\text { vomiting }\end{array}$ & $\begin{array}{l}\text { No or infrequent } \\
\text { vomiting }\end{array}$ \\
\hline $0-<10 \%$ & 59 & $41(69 \cdot 5)$ & $18(30 \cdot 5)$ \\
$\geqslant 10 \%$ & 11 & $11(100)$ & 0 \\
Total & 70 & $52(74 \cdot 3)$ & $18(25 \cdot 7)$ \\
\hline
\end{tabular}

There was a significant association between frequent vomiting and pathologically increased fractional reflux time $(\geqslant 10 \%)$ $\left(x^{2}=4.52, \mathrm{p}=0.034\right)$.
$(6 \cdot 4) \%)$, and one infant had gastritis and normal oesophageal histology (fractional reflux time $7 \cdot 6 \%$ ).

Sleep disturbance was observed in 10 infants $(14 \cdot 3 \%)$. There was no significant association with the severity of GOR. Five infants had a fractional reflux time of $<5 \%$, four of $\geqslant 5-<10 \%$, and one of $\geqslant 10 \%\left(\chi^{2}=1 \cdot 06\right.$, $\mathrm{p}=0.59)$.

There was no significant difference in mean fractional reflux time between infants who were breast or bottle fed at the time of $\mathrm{pH}$ monitoring $(6.0(3.8) v 5.6(5.0) \%, \mathrm{p}=0.75)$ or between infants with and without feeding difficulties $(5 \cdot 6$ $(4.9) \% v 5.7(4.7) \%, \mathrm{p}=0.89)$. Of the 26 infants with backarching during feeding, 15 $(57 \cdot 7 \%)$ had a fractional reflux time $<5 \%$, seven $(26.9 \%)$ of $\geqslant 5-<10 \%$, and four $(15.4 \%)$ of $\geqslant 10 \%\left(\chi^{2}=0.006, p=0.99\right)$. There was no significant difference in fractional reflux time between infants with and without backarching $(5 \cdot 9(5 \cdot 2) v 5 \cdot 5(4 \cdot 5), \mathrm{p}=0 \cdot 76)$.

\section{GASTROSCOPY}

Endoscopic examination of the upper gastrointestinal tract was undertaken in infants in whom there was a clinical suspicion of oesophagitis based on $\mathrm{pH}$ monitoring results and frequency of vomiting. Forty patients underwent gastroscopy with routine oesophageal biopsies (mean age $4.4(2 \cdot 1)$ months). Seven $(17 \cdot 5 \%)$ had histological evidence of oesophagitis ${ }^{26}$; all were aged 3 months or older. Of the 26 infants with backarching, 14 had oesophageal biopsies. Of these, only four $(28.6 \%)$ had evidence of oesophagitis $\left(\chi^{2}=0 \cdot 183, \mathrm{p}=0 \cdot 17\right)$.

\section{BARIUM SWALLOW}

Twenty six infants had upper gastrointestinal barium studies. The severity of reflux on barium study was defined as that reported by the radiologist at the time of fluoroscopy. Eleven of $26(42 \cdot 3 \%)$ were reported as normal, nine $(34.6 \%)$ as showing mild GOR, and six $(23 \cdot 1 \%)$ as showing significant GOR. A hiatus hernia was identified in only one infant. This child had ulcerative oesophagitis on gastroscopy and subsequently underwent fundoplication. The relationship between the results of barium studies and fractional reflux time is summarised in table 3 . The weighted $\kappa$ test $^{25}$ showed only fair agreement $(\kappa=0.395$, $\mathrm{p}=0.02$ ), but a non-significant trend towards

Table 3 Severity of GOR on upper gastrointestinal barium study in relation to fractional reflux time

\begin{tabular}{llllr}
\hline & \multicolumn{4}{c}{ Fractional reflux time } \\
\cline { 2 - 5 } & $0-<5 \%$ & $\geqslant 5-<10 \%$ & $\geqslant 10 \%$ & $\Sigma$ \\
\hline GOR on barium study & 8 & 2 & 1 & 11 \\
$\quad$ Normal & 3 & 3 & 3 & 9 \\
Mild & 2 & 1 & 3 & 6 \\
Significant & 13 & 6 & 7 & 26 \\
\hline
\end{tabular}

The weighted $\kappa$ test showed only fair agreement $(\kappa=0.395$, $p=0 \cdot 02$ ). However, total numbers were small and there appeared to be a non-significant trend towards more severe radiological abnormalities in those with pathological reflux. 
Table 4 Use of antireflux medications at the time of hospital admission in relation to severity of GOR; values are number (\%)

\begin{tabular}{lllrrrr}
\hline Fractional reflux time & No & Nil & Thickener & Antacids & Ranitidine & Cisapride \\
\hline $0-<5 \%$ & 40 & $4(10 \cdot 0)$ & $26(65 \cdot 0)$ & $16(40 \cdot 0)$ & $25(62 \cdot 5)$ & $26(65 \cdot 0)$ \\
$\geqslant 5-<10 \%$ & 19 & $2(10 \cdot 5)$ & $13(68 \cdot 4)$ & $6(31 \cdot 6)$ & $11(57 \cdot 9)$ & $14(73 \cdot 7)$ \\
$\geqslant 10 \%$ & 11 & 0 & $8(72 \cdot 7)$ & $5(45 \cdot 5)$ & $8(72 \cdot 7)$ & $9(81 \cdot 8)$ \\
Total & 70 & $6(8 \cdot 5)$ & $47(67 \cdot 1)$ & $27(38 \cdot 6)$ & $44(62 \cdot 9)$ & $49(70 \cdot 0)$
\end{tabular}

Infants with minimal reflux were as likely to have been treated with multiple antireflux medications as infants with severe reflux.

more severe radiological abnormalities existed in these with pathological reflux. Marked radiological abnormalities were present in only three of 19 with fractional reflux time $<10 \%$ compared with three of seven with fractional reflux time $\geqslant 10 \%$.

\section{ANTIREFLUX TREATMENT}

The majority of patients were on antireflux medications at the time of hospital admission but remained irritable. Fifteen infants $(21 \cdot 4 \%)$ had received 'colic mixtures' which contained medications such as anticholinergic drugs and phenobarbitone. Only 14 infants $(20.0 \%)$ were being postured $30^{\circ}$ head-up at the time of admission. Forty seven infants $(67 \cdot 1 \%)$ were treated with food thickener, $27(38.6 \%)$ with antacids, $44(62.9 \%)$ with ranitidine, and 49 $(70.0 \%)$ with cisapride. All 11 infants with significant GOR (fractional reflux time $\geqslant 10 \%$ ) had been on antireflux treatment until 48 hours before oesophageal $\mathrm{pH}$ monitoring (nine on food thickener, six on antacids, nine on cisapride, and eight on ranitidine). Despite this treatment symptoms were inadequately controlled. Of the seven infants with oesophagitis, five were on treatment with cisapride and ranitidine, one infant was on cisapride alone, and one infant on ranitidine alone (table 4).

\section{PROVISIONAL AND FINAL DIAGNOSES}

As a result of investigations the provisional diagnosis of irritability associated with pathological GOR was confirmed in 22 of 70 $(31.4 \%)$ infants. These patients had either moderate to severe reflux on $\mathrm{pH}$ monitoring or a close relationship between episodes of reflux and irritability. Antireflux medications were stopped in 20 patients $(28.6 \%)$, and started in five infants with moderate reflux who were not currently on antireflux medications. One infant was referred for fundoplication at the age of 4.5 months, and one infant was changed from ranitidine to omeprazole.

\section{Discussion}

The first aim of our study was to define the role of GOR as a cause of infant irritability. The age distribution in our study was typical of other studies of irritable infants with most infants aged between 2 and 4 months. ${ }^{1-4}$ Pathological GOR was uncommon in the infants under 3 months (one of $24 ; 4 \cdot 2 \%$ ). Furthermore, none of the infants under 3 months had histological evidence of oesophagitis. The usual trend in infancy is for a decline in severity of GOR during the first year of life. ${ }^{17}$ The opposite trend in our study suggests that irritability occurring during the first three months, that is in the typical age group for excessive crying, is not usually caused by pathological GOR. About one fifth of the infants aged 3 months or older had pathological reflux, implying that excessive crying is more likely to be associated with pathological GOR in this age group. The higher prevalence in older infants may in part be due to selection bias as patients with significant vomiting were more likely to be referred to a gastroenterologist.

The second aim of our study was to develop clinical predictors of pathological reflux in irritable infants. Haematemesis was associated with oesophagitis in three of four infants and was a useful predictor of excessive GOR. Frequent vomiting or regurgitation was observed in about three quarters of infants. All infants with pathological reflux presented with frequent vomiting, and none of the infants with absent or infrequent vomiting had pathological reflux (table 2). These findings suggest that significant GOR is unlikely in the absence of frequent vomiting and that 'silent' GOR is an uncommon cause of irritability. Other authors have also found that oesophagitis is virtually always associated with frequent vomiting or frank regurgitation in infancy. ${ }^{12} 1316$

Half of the infants presented with perceived feeding difficulties. There was no significant difference in age between infants with and without feeding difficulties. Crying and backarching during feeding have recently been proposed as specific symptoms of reflux oesophagitis. ${ }^{27}$ In our study, backarching was more common in infants with only minor reflux than in those with pathological GOR. About three quarters of infants with a history of backarching had no histological evidence of oesophagitis. Our data on oesophagitis should be interpreted carefully as the majority of infants were on some antireflux medication at the time of hospital admission. Other investigators have found a poor correlation between the presence of oesophagitis and backarching with feeding resistance. ${ }^{15}$ It appears that although backarching is a recognised symptom of odynophagia due to oesophagitis, it is unrelated to GOR in the majority of irritable infants. Presence or absence of sleep disturbance was also not associated with pathological GOR in our study group.

Irritability is equally common in breast and bottle fed infants. ${ }^{9}$ In our study, $80 \%$ of infants were bottle fed at the time of hospital admission. Failure to establish breast feeding was common, but we did not attempt to establish whether this may have adversely affected the mother-child relationship or was secondary to the infant's irritability. Breast and bottle fed infants in the study population had similar degrees of reflux. Other investigators have found that healthy breast fed neonates had a lower incidence of GOR than those who were bottle fed. ${ }^{28}$ Many of the infants in our study had gone through a series of formula changes for presumed milk intolerance. Some had received up to six different formulas in a short 
time. Improvement of irritability was often only transient and may have represented a placebo effect.

Failure to thrive is a well recognised complication of pathological GOR. ${ }^{12} 13$ Poor weight gain results from energy losses due to vomiting and decreased feeding. In our population, about one sixth of infants presented with failure to thrive. We found no association between poor weight gain and the severity of GOR. This finding is probably due to the small numbers of infants with significant GOR in our study, especially in the group under 3 months of age. There was no significant difference in $\mathrm{Z}$ scores for weight for age between infants with and without feeding difficulties suggesting that most of these infants maintained a sufficient intake despite their perceived feeding difficulties.

Barium studies have a limited role in the diagnosis of pathological GOR as quantification of reflux is difficult. ${ }^{29}$ In the 23 infants who underwent a barium swallow agreement with $\mathrm{pH}$ monitoring results was only poor to fair. The main role of radiology is to identify anatomical abnormalities such as a hiatus hernia, and it should be complementary to $\mathrm{pH}$ monitoring and upper gastrointestinal endoscopy. ${ }^{29}$

The majority of infants were being treated with antireflux medications at the time of tertiary level referral but remained irritable. The use of antireflux medication bore a poor correlation with the severity of GOR. All 11 infants with significant reflux were on antireflux medications, and more than two thirds of these had received cisapride and/or ranitidine. Only six of 59 infants $(10 \cdot 2 \%)$ with non-pathological degrees of reflux (fractional reflux time $<10 \%$ ) were untreated suggesting that a large proportion of infants were treated for reflux unnecessarily.

Parents may experience feelings of failure, anxiety, and distress when unable to console their crying infant. In this situation, if no other organic cause is identified, diagnosis with conditions such as GOR or food intolerance may be a convenient strategy to relieve parental self doubt. Given their relative safety many physicians prescribe antireflux medications generously even if clinical signs of GOR are absent or equivocal. A trial of antireflux medications should, however, be limited in time, and drugs should be discontinued if irritability persists. ${ }^{13}$ Our study suggests that pathological GOR is a cause of irritability mainly in infants over 3 months of age who present with overt regurgitative reflux. Oesophageal $\mathrm{pH}$ monitoring should not routinely be used to investigate irritable infants under 3 months of age.

The authors wish to thank Mrs Dianne Simpson, Gastroenterology Department, for her invaluable technical assistance with the oesophageal $\mathrm{pH}$ monitoring. We would also like to thank $\mathrm{Mr}$ Ted Byrt, Clinical Epidemiology and Biostatistics Unit, Royal Children's Hospital, for his help with the statistical analysis of the study.
1 Walker AM, Menahem S. Normal early infant behaviour patterns. $\mathcal{f}$ Paediatr Child Health 1994; 30: 260-2.

2 Michelsson K, Rinne A, Paajanen S. Crying, feeding and sleeping patterns in 1 to 12 -month-old infants. Child Care Health Dev 1990; 16: 99-111.

3 Wessel MA, Cobb JC, Jackson EB, Harris GS Jr, Detwiler AC. Paroxysmal fussing in infancy, sometimes called 'colic'. Pediatrics 1954; 14: 421-35.

4 Brazelton TB. Crying and colic. Infant Mental Health

Fournal 1990; 11: 349-56.
5 McKenzie S. Troublesome crying in infants: effect of advice to reduce stimulation. Arch Dis Child 1991; 66: advice to

6 Rautava P, Helenius H, Lahtonen L. Psychosocial predisposing factors for infantile colic. $B M \mathcal{M}$ 1993; 307: 600-4.

7 Zuckerman B, Bauchner H, Parker S, Cabral H. Materna depressive symptoms during pregnancy. $f$ Dev Behav Pediatr 1990; 11: 190-4.

8 Miller AR, Barr RG, Eaton WO. Crying and motor behavio of six-week-old infants and postpartum maternal mood. Pediatrics 1993; 92: 551-8.

9 Barr RG. Colic and gas. In: Walker WA, Durie PR, Hamilton JR, Walker-Smith JA, Watkins JB, eds. Pediatric gastrointestinal disease. Philadelphia: B C Decker, 1991: 55-61.

10 Browne G, Lillystone $D$. Renal disease presenting as severe unremitting colic. Med f Aust 1991; 154: 93-4.

11 Iacono G, Carroccio A, Montalto G, et al. Severe infantile colic and food intolerance: a long-term prospective study. colic and food intolerance: a long-term prospec

12 Ryan P, Lander M, Ong TH, Shepherd R. When does reflux oesophagitis occur with gastro-oesophageal reflux in infants? A clinical and endoscopic study, and correlation with outcome. Aust Paediatr F 1983; 19: 90-3.

13 Shepherd RW, Wren J, Evans S, Lander M, Ong TH. Gastroesophageal reflux in children. Clinical profile, course and outcome with active therapy in 126 cases. Clin Pediatr (Phila) 1987; 26: 55-60.

14 Vandenplas Y, Ashkenazi A, Belli D, et al. A proposition for the diagnosis and treatment of gastro-oesophageal reflux disease in children: a report from a working group on gastro-oesophageal reflux disease. Eur F Pediatr 1993; 152: 704-11.

15 Dellert SF, Hyams JS, Treem WR, Geertsma MA. Feeding resistance and gastroesophageal reflux in infancy. $\mathcal{F}$ Pediatr Gastroenterol Nutr 1993; 17: 66-71.

16 Hyams JS, Ricci A Jr, Leichtner AM. Clinical and laboratory correlates of esophagitis in young children. $\mathcal{f}$ Pediatr tory correlates of esophagitis in you
Gastroenterol Nutr 1988; 8: 52-5.

17 Vandenplas Y, Goyvaerts $\mathrm{H}$, Helven $\mathrm{R}$, Sacré $\mathrm{L}$. Gastroesophageal reflux, as measured by 24 -hour $\mathrm{pH}$ monitoring, in 509 healthy infants screened for risk of sudden infant death syndrome. Pediatrics 1991; 88: $834-40$.

18 Sondheimer JM. Continuous monitoring of distal esophageal $\mathrm{pH}$ : a diagnostic test for gastroesophageal reflux in infants. $\mathcal{F}$ Pediatr 1980; 96: 804-7.

19 Vandenplas Y, Belli D, Boige N, et al. A standardized protocol for the methodology of esophageal $\mathrm{pH}$ monitoring and interpretation of the data for the diagnosis of gastroesophageal reflux. ESPGAN - society statement. $\mathcal{F}$ Pediatr Gastroenterol Nutr 1992; 14: 467-71.

20 Barr RG, Woolridge J, Hanley J. Effects of formula change on intestinal hydrogen production and crying and fussing on intestinal hydrogen production and crying and

21 Moore DJ, Robb TA, Davidson GP. Breath hydrogen response to milk containing lactose in colicky and noncolresponse to milk containing lactose in colicky
icky infants. $¥$ Pediatr 1988; 113: $979-84$.

22 O'Donovan JC, Bradstock AS. The failure of conventional drug therapy in the management of infantile colic. $A m \mathcal{F}$ Dis Child 1979; 133: 999-1001.

23 Strobel CT, Byrne WJ, Ament ME, Euler AR. Correlation of esophageal lengths in children with height: application of the Tuttle test without prior esophageal manometry. $\mathcal{J}$ Pediatr 1979; 94: 81-4

24 Dibley MJ, Staehling N, Nieburg P, Trowbridge FL Interpretation of $\mathrm{Z}$-score anthropometric indicators derived from the international growth reference. $\mathcal{f}$ Clin Nutr 1987; 46: 749-62.

25 Byrt T, Bishop J, Carlin J. Bias, prevalence and kappa. $\mathcal{f}$ Clin Epidemiol 1993; 46: 423-9.

26 Black DD, Haggitt RC, Orenstein SR, Whitington PF. Esophagitis in infants. Morphometric histological diagnosis and correlation with measures of gastroesophageal nosis and correlation with measures of gastr.
reflux. Gastroenterology 1990; 98: 1408-14.

27 Orenstein SR, Putnam PE, Shalaby PM, et al. Symptoms of infantile reflux esophagitis, using validated techniques for infantile reflux esophagitis, using validated techniques for symptoms

28 Heacock HJ, Jeffery HE, Baker JL, Page M. Influence of breast versus formula milk on physiological gastroesophageal reflux in healthy, newborn infants. $f$ Pediat Gastroenterol Nutr 1992; 14: 41-6.

29 Leonidas JC. Gastroesophageal reflux in infants: role of the upper gastrointestinal series. AfR 1984; 143: 1350-1. 